\title{
Corneal endothelial changes induced by pars plana vitrectomy with silicone oil tamponade for retinal detachment
}

\author{
CORINA CRISTINA COMAN (CERNAT) ${ }^{{ }^{*}}$, MIHNEA MUNTEANU ${ }^{1 *}$, DANIEL MALITA $^{2 *}$, \\ SIMONA STANCA ${ }^{3 *}$, STELLA IOANA PATONI (POPESCU) ${ }^{1}$, OVIDIU MUSAT ${ }^{4}$, SERBAN NEGRU $^{5}$, \\ HOREA FEIER $^{6}$, OLIMPIU LADISLAU KARANCSI ${ }^{7}$ and COSMIN ROSCA ${ }^{8}$
}

\begin{abstract}
Departments of ${ }^{1}$ Ophthalmology, and ${ }^{2}$ Radiology and Medical Imaging, 'Victor Babes' University of Medicine and Pharmacy, 300041 Timisoara; ${ }^{3}$ Department of Pediatrics, 'Carol Davila' University of Medicine and Pharmacy, 050474 Bucharest; ${ }^{4}$ Department of Ophthalmology, 'Dr. Carol Davila' Central Military Emergency University Hospital, 010825 Bucharest; ${ }^{5}$ Department of Oncology, 'Victor Babes' University of Medicine and Pharmacy, 300239 Timisoara; Departments of ${ }^{6}$ Cardiovascular Surgery, and ${ }^{7}$ Oral Implantology and Prosthetic Restorations on Implants,

'Victor Babes' University of Medicine and Pharmacy, 300041 Timisoara;

${ }^{8}$ Department of Ophthalmology, Oculens Clinic, 400501 Cluj-Napoca, Romania
\end{abstract}

Received March 10, 2021; Accepted April 9, 2021

DOI: $10.3892 / \mathrm{etm} .2021 .10393$

\begin{abstract}
Silicone oils are effective intraocular tamponade agents in the treatment of severe retinal detachments, because they maintain the adhesion between neurosensory retina and retinal pigment epithelium, thanks to their ability to remove aqueous humor from the surface of the retina. To understand their effectiveness, it is important to know the characteristics of silicone oils. Patients should be closely monitored due to many complications associated with intraocular silicon oil, such as inflammatory reaction, raised intraocular pressure, refraction disorders, cataract, and emulsification. This study presents corneal endothelial changes and some intraocular complications caused by silicone oil used as an intraocular tamponade agent in the case of vitrectomy for complex retinal detachments. The aim of the study was to demonstrate the damage of corneal endothelial cells after the use of silicone oil in patients with retinal detachment surgery. Endothelial specular microscopy measurements were performed and the
\end{abstract}

Correspondence to: Dr Ovidiu Musat, Department of Ophthalmology, 'Dr. Carol Davila' Central Military Emergency University Hospital, 134 Plevnei Street, 010825 Bucharest, Romania E-mail: ovidiumusat@yahoo.com

Dr Serban Negru, Department of Oncology, 'Victor Babes' University of Medicine and Pharmacy, 59 Ciprian Porumbescu Street, 300239 Timisoara, Romania

E-mail: snegru@yahoo.com

"Contributed equally

Key words: silicone oil, retinal detachment, intraocular complications, specular microscopy, corneal endothelial cell count changes of the following parameters demonstrated the corneal damage: Mean cell density, coefficient of variation, average cell area, percentage of hexagonal cells, and corneal thickness. Three months postoperatively, a statistically significant decrease was observed in the following analyzed parameters: Mean cell density $(\mathrm{P}=0.04)$, and percentage of hexagonal cells $(\mathrm{P}=0.002)$; the remaining parameters also had a linear decrease (coefficient of variation, average cell area), but were statistically insignificant. Three months postoperatively, the corneal thickness presented a slight increase. Silicone oils are powerful tools when used wisely and within the limits of their use. These are often recommended in cases of severe detachment of the retina in patients at high risk of experiencing intraoperative complications.

\section{Introduction}

The research regarding intraocular tamponade products is one of the most challenging and interesting areas in ophthalmology; it began more than a century ago. In the early 1960s, Dr Paul Cibis began to inject silicon oil in vitro to animals, in order to provide a permanent support to the retina, but the anatomical and functional outcomes were not the expected ones (1-3). In The Netherlands, Zivojnović popularized the technique and contributed greatly to its use (4). In 1992, the Silicone Oil Study, a prospective, multicenter, randomized, controlled clinical trial showed that silicone oil was superior to SF6 and equivalent to the perfluorocarbon gas in the treatment of vitreoretinal proliferation. Following these studies, the USA Food and Drug Administration (FDA) approval for its use as a tamponade product in 1994 triggered marketing and use worldwide (5-9).

The first indications of silicone oil use were: Ocular trauma, severe proliferative diabetic retinopathy, complicated retinal detachment caused by proliferative retinopathy or viral retinitis and giant retinal tears, due to the silicone oil ability to displace 
aqueous humor from the retinal surface maintain the application of the neurosensory retina to the retinal pigment epithelium (10).

At present, new indications for silicone oil use are possible, such as chronic and persistent macular hole, chronic uveitis with hypotony, retinal detachment due to macular hole in myopic eyes, and colobomatous retinal detachment $(11,12)$. A great advantage of the silicone oil is that it provides support over a long period of time until retinal recovery occurs.

In the case of retinal detachment, silicone oil is usually removed after 3-6 months, because it is thought that it is enough for the eye to recover with minimal risk for the development of proliferative vitreoretinopathy (13).

In addition, in patients who travel by air, in children and elderly patients (who cannot maintain a correct postoperative position), silicone oil is a first choice (14).

Retinal detachment surgery is a relative emergency surgery meaning that patients undergo this surgery within $24-48 \mathrm{~h}$ after the onset of vision loss. Furthermore, surgery is the only possible remedy in the event of retinal detachment. Different interventions exist and the choice is made according to the characteristics of the patient's pathology.

The objectives of the surgery sought in retinal detachment are: To heal or plug the tear in the retina, to puncture the liquid present between the two retinal layers, to re-approach the neuroepithelium of the pigment epithelium in order to reconstitute the anatomically and physiologically normal retina, and to create an adhesive scar between the retina and the fundus of the eye, in order to stabilize the retina and prevent recurrence $(15,16)$.

Silicone oil is injected at the end of the surgical procedure, when membrane dissection has already been performed, all lesions are sealed and released from the traction forces. Air-fluid exchange occurs and between $3-4 \mathrm{~cm}^{3}$ of silicone oil of 1,000 or 5,000 centistokes is injected (17).

In the postoperative period, the patient should be placed in ventral decubitus, in order to avoid the contact of silicone oil with the cornea and the posterior face of the intraocular lens (18).

Large population-based studies of retinal detachment have an annual incidence of about 1 in 10.000, and a family aggregation study estimated a $3 \%$ lifetime risk at 85.2 years (19). White and Asian populations have similar rates, with a lower incidence among individuals of African descent $(20,21)$. The average age of presentation is approximately 60 years, the sexes being equally affected.

Due to the fact that the surgery for retinal detachment involves retrobulbar anesthesia and to the potential complications induced by the surgery and silicone oil, patients were screened for other associated disease and treatment options (22-29).

However, post-operatory complications of the silicone oil tamponade also occur. The use of silicone oils has no short- or medium-term side effects. Patients should be monitored regularly. They are usually seen several times in the first months, then 3-4 times a year, as long as silicone oil persists in the eye.

Early complications include: i) Post-operatory ocular inflammation that is almost constant. It is related to severe trauma and initial pathology. However, silicone oil, especially heavy silicone oil, is considered pro-inflammatory. Serum anti-silicon antibodies were found in $35.7 \%$ of patients with silicone tamponade, and up to $83 \%$ of those with intraocular silicone oil (30). ii) Variation of intraocular pressure pertains to early postoperative ocular hypertension which is often evident after silicone oil tamponade. It is related to immediate post-operatory inflammation and, more rarely, to excessive filling, which requires a partial discharge of silicone oil present. Chronic ocular hypertonia may occur, especially in the case of prolonged tamponade. This may be related to decompensation of pre-existing hypertension, prolonged steroid prescription, chronic trabeculitis through trabecular adhesions, or migration of silicon microemulsion particles into trabecular meshwork $(31,32)$.

Medium- or long-term complications include: i) Refraction disorders: Due to its refractive index, silicone oil tamponade causes a change in the patient's refraction. Silicone is responsible for a hypermetropic of 3-7 diopters in phakic eyes and a myopia of 5 diopters in aphakic eyes. It is not just a complication, but rather a disorder that will last only during the intraocular presence of silicone (30). ii) The appearance of cataracts is a frequent complication after silicone oil tamponade. The contact between the silicone bubbles and the posterior capsule of the lens prevents the diffusion of nutrients and leads to the development of a posterior subcapsular cataract. After silicone oil tamponade $62.5 \%$ of patients develop cataracts up to 3 months, while the incidence is $100 \%$ over 6 years (33). iii) Emulsification is the second most common complication associated with silicone oil tamponade. It is defined as the fragmentation of a single silicone bubble in more bubbles of different diameters. Emulsification changes the silicone tamponade power resulting in a decrease in its ability to block dehiscence. Silicone microbubbles may be able to migrate to the anterior chamber and to the trabecular meshwork, and can cause edema keratopathy or intraocular hypertension (8). Some authors observed emulsification 2 weeks after injection. Previous findings showed that, the average emulsification time of silicone 1,000 was 13.2 months (5-24 months), which was significantly higher than the average tamponade time $(34,35)$. iv) Contact of silicone oil with corneal endothelium can cause corneal decompensation and band keratopathy. Complications are secondary to the migration of silicone oil into the anterior chamber, resulting in discontinuity of endothelial metabolism and precipitation of calcium salts (36).

Literature reported an incidence of keratopathy of up to $30 \%$ of patients after 6 months of treatment $(37,38)$.

Thus, the aim of the present study was to evaluate the loss of corneal endothelial cells in patients undergoing complex retinal detachment, which required internal tamponade with silicone oil of 1,000 centistokes.

\section{Materials and methods}

Ethics approval and patient consent. The present study is a retrospective, interventional, comparative assessment with consecutive enrolment of patients diagnosed with rhegmatogenous or tractional retinal detachment requiring surgery. All subjects provided written informed consent to be subjected to ocular surgery for retinal detachment, prior to enrolment. Ethics Committee (number 401) approval was obtained from 'Dr. Carol Davila' Central Military University Emergency Hospital Bucharest and was conducted in accordance with the 
Declaration of Helsinki and with the International Standard of Good Clinical Practice (ICH-GCP E6 Step 4).

Patients. A total of 20 patients ( 7 males, 13 females, aged 54-70 years) diagnosed with rhegmatogenous or traction retinal detachment that requires as a method of treatment posterior vitrectomy adjusted with silicone oil endotamponade, were selected from the Department of Ophthalmology of the 'Dr. Carol Davila' Central Military Emergency University Hospital in Bucharest.

The inclusion criterion was the diagnosis of rhegmatogenous or tractional retinal detachment requiring surgery. The exclusion criteria included any coexisting corneal or retinal disease, history of eye trauma or any other eye intervention performed in the past other than cataract.

The patients were divided into 2 groups: Group 1 (9 females, 3 males, aged, aged 54-70 years) included subjects who had a natural lens in the operated eye and group 2 (4 females, 4 males, aged 58-69 years) included those who were pseudophakic in the eye where the surgery was performed.

Methods. Non-contact corneal specular microscopy was used to measure the following parameters: Mean endothelial cell density (MCD), average cell area (AVG), coefficient of variation in cell size $(\mathrm{CV})$, percentage of hexagonal cells (HEX) and corneal thickness (CT) at baseline representing surgery and then 3 months after the surgery was completed. Of the several measurements, the one that showed maximum counted endothelial cells was chosen. As a control method, the patient's other unoperated eye was used.

Surgery was performed under retrobulbar anesthesia by the same surgeon for all the patients. After topical disinfection with povidone-iodine, a sterile field and lid speculum were applied. The surgery consisted of: 25 gauge total posterior vitrectomy, locating the retinal hole/holes and performing a laser blockage around the hole and once the retinal attachment was obtained the air exchange was changed to silicone oil of 1,000 centistoke.

Preoperatively and 3 months postoperatively, bilateral corneal specular microscopy was performed in all the patients to count endothelial cells, coefficient of variation, central cell area, percentage of hexagonal cells and corneal thickness.

Patients were subsequently discharged after confirmation of retinal attachment and then re-evaluated after three months, using corneal specular microscopy; the results were recorded.

All determinations of the studied values were performed using similar working techniques. For the processing and systematization of the data, the Excel program of the Microsoft Office 365 suite was used. The graphical representations, as well as the statistical analysis of the data were performed using the same program, together with 'add-ins', such as WinStat and XL-stat. For the calculation of the statistical significance of the obtained results, online support was provided by Professor Richard Lowry-Vassar College Poughkeepsie (Poughkeepsie, NY, USA), through the link www.vassarstats.net.

Statistical analysis. In order to establish the relationships between various values of the analyzed coefficients, the average values were calculated, as well as the mean \pm standard deviation or standard error of Student's test (t-test), and its

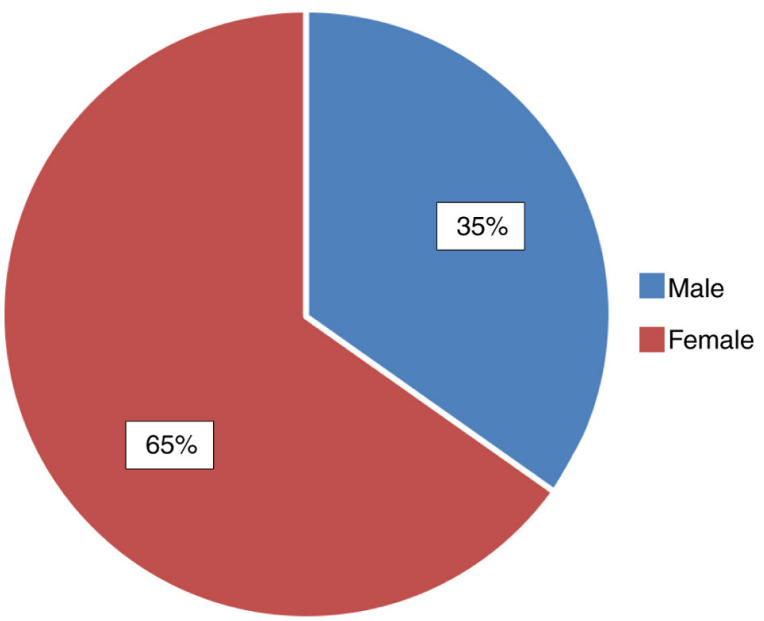

Figure 1. Patient distribution by sex. Patients included in the study were predominantly men.

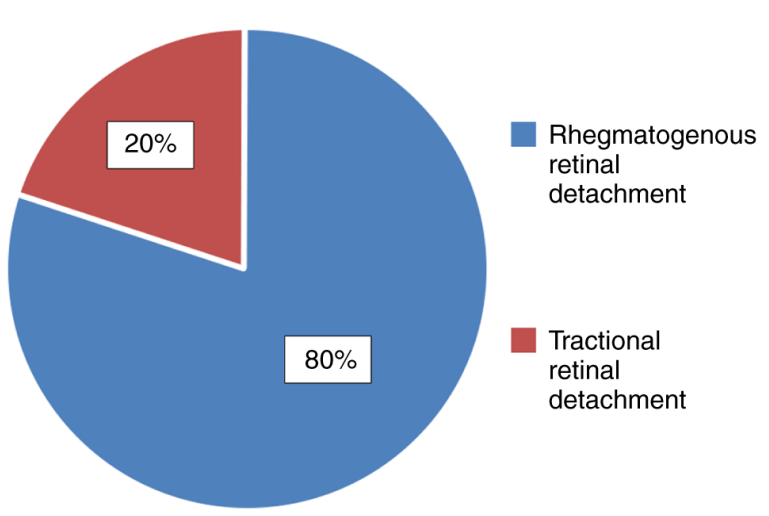

Figure 2. Patient distribution according to their diagnosis. In total, $20 \%$ of patients were diagnosed with rhegmatogenous retinal detachment and $80 \%$ with tractional retinal detachment.

statistical significance was represented by P-values. The statistical significance of the results was interpreted according to the value of the coefficient $\mathrm{p}$ : $\mathrm{P}>0.05$ indicated the results were not statistically significant; for P-values between 0.05 and 0.001 the results were considered highly statistically significant, while P-values $<0.001$ were considered very highly statistically significant.

\section{Results}

Patients. Patient demographic data are presented in Fig. 1. Patient surgical indications were rhegmatogenous and tractional retinal detachment (Fig. 2). Patient distribution according to age is presented in Fig. 3.

Various parameters. MCD, CV, AVG, HEX and CT values of all groups at baseline, postoperative and three months postoperatively are shown in Figs. 4-8. For the parameters MCD, AVG, CV, HEX a linear decrease was observed both immediately postoperatively (MCD with $1.22 \%$, AVG with $12.05 \%$, CV with $7.50 \%$, HEX with 4.19\%) (Table I) and after 3 months (MCD with $3.61 \%$, AVG with $14.04 \%$, CV with $14.08 \%$, HEX with $7.78 \%$ ) (Table II). 


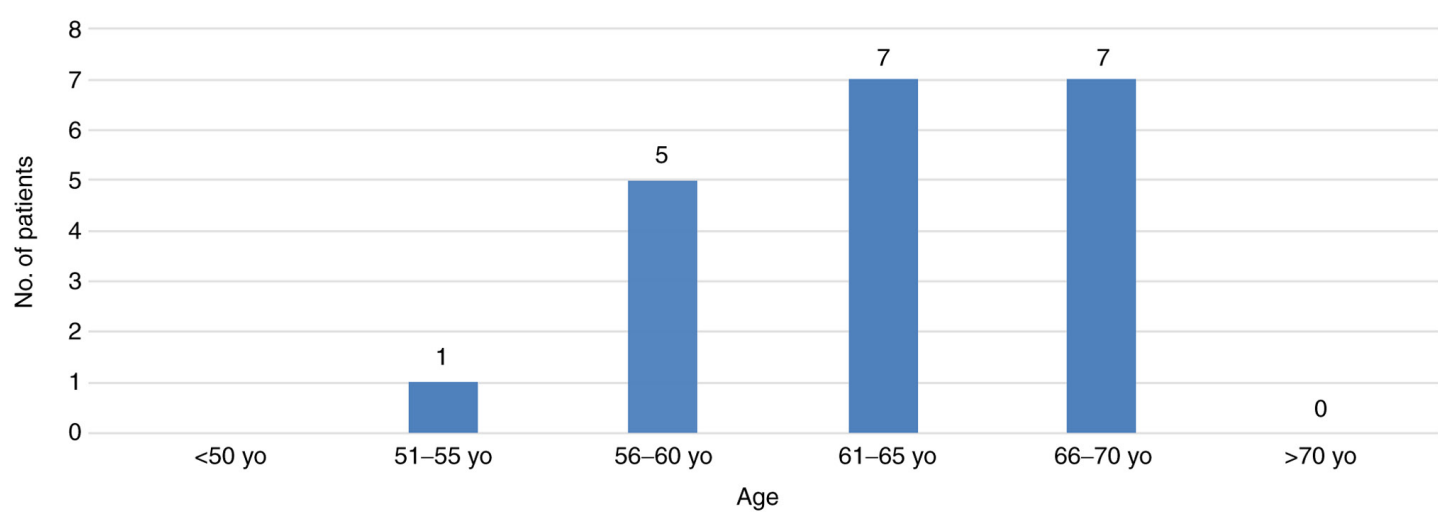

Figure 3. Patient distribution according to age. The majority of patients were over 60 years of age.

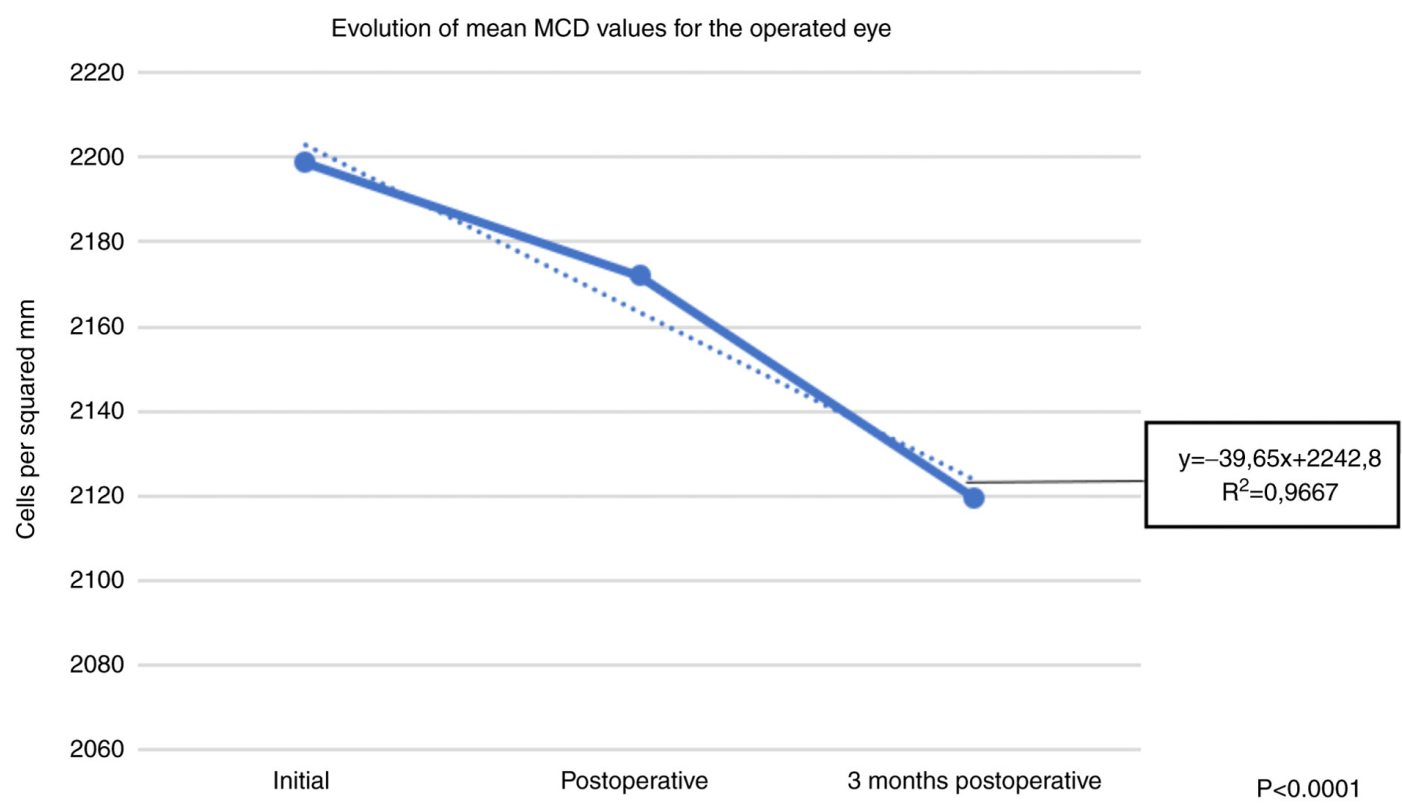

Figure 4. Evolution of mean MCD values for the operated eye.

Evolution of mean $C D$ values for the operated eye

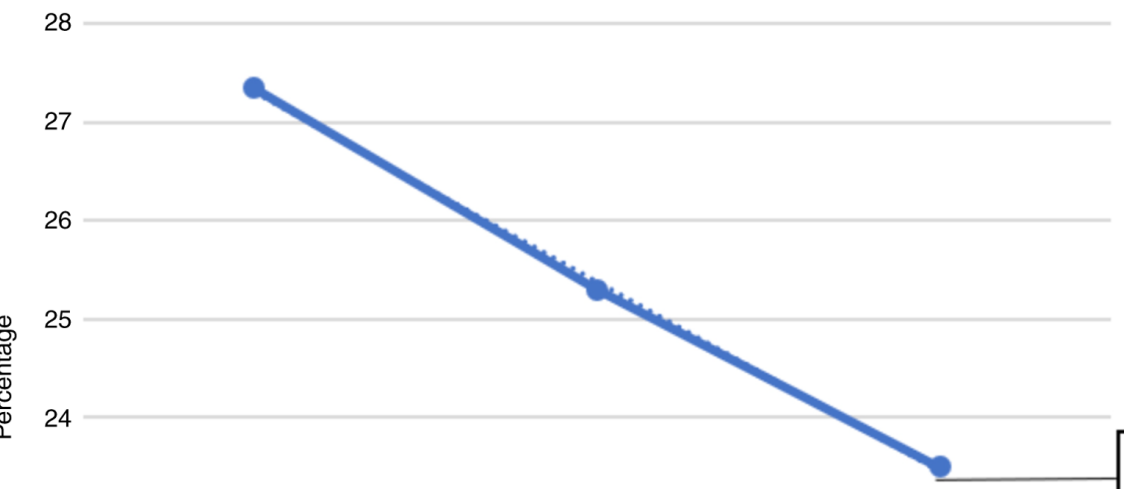

23

$y=-1,925 x+29,233$ $R^{2}=0,9986$

22

21

Initial

Postoperative

3 months postoperative

$P<0.0001$

Figure 5. Evolution of mean CV values for the operated eye. 


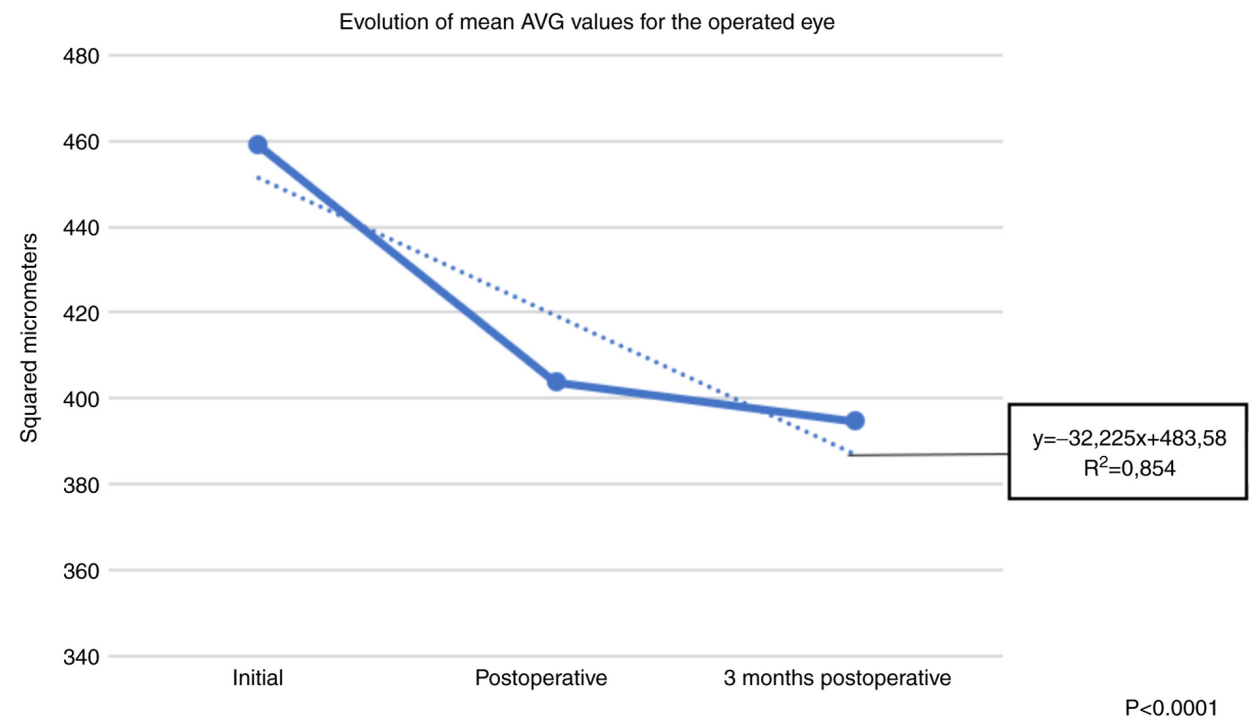

Figure 6. Evolution of mean AVG values for the operated eye.
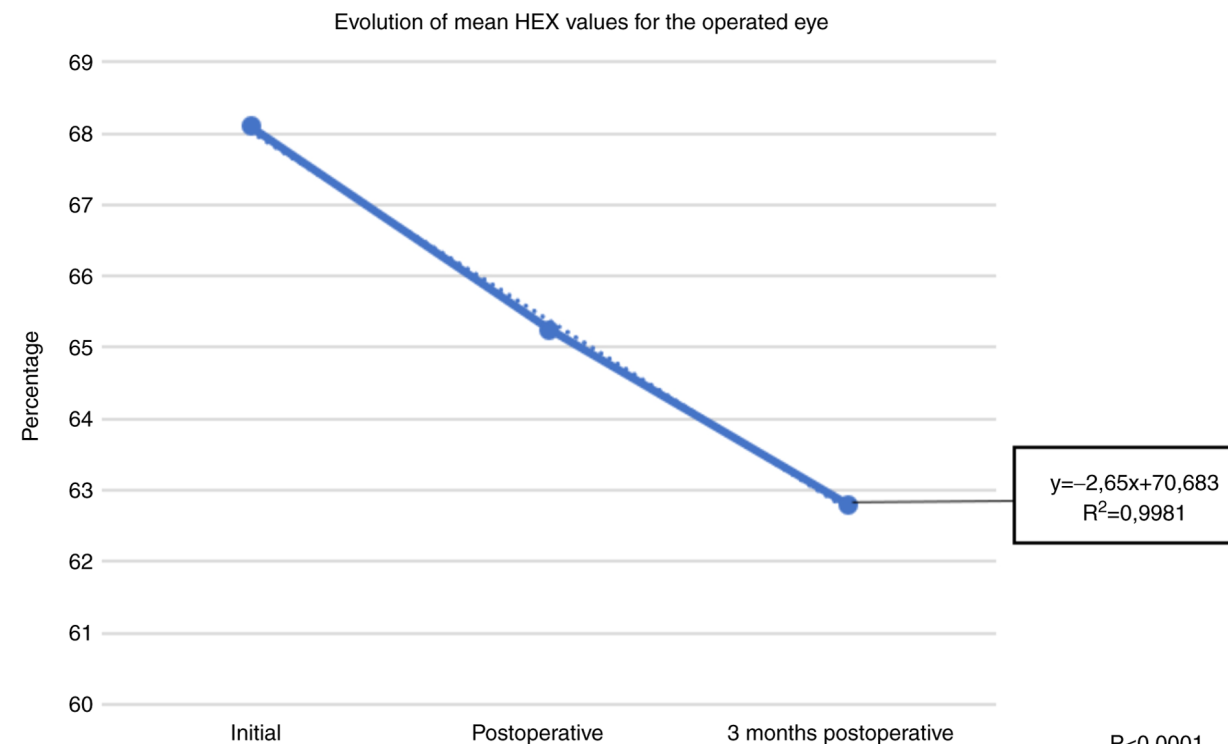

$\mathrm{P}<0.0001$

Figure 7. Evolution of mean HEX values for the operated eye.

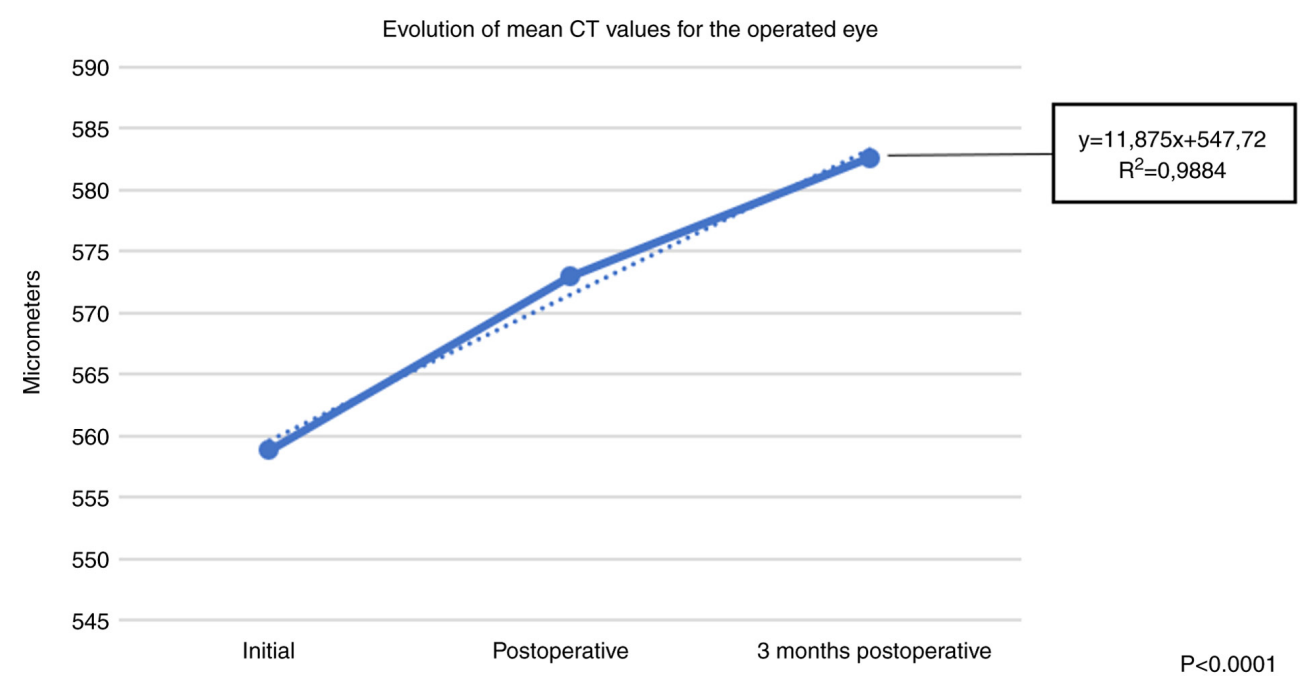

Figure 8. Evolution of mean CT values for the operated eye. 
Table I. Comparison between the postoperative values of the analyzed parameters for all patients.

\begin{tabular}{|c|c|c|c|}
\hline Variables & Operated eye & & Non-operated eye \\
\hline MCD average postoperative & $2,171.95(-1.22 \%)$ & & $2,525.6$ \\
\hline Standard deviation & 564.92 & & 466.69 \\
\hline Standard error & & 163.851 & \\
\hline $95 \% \mathrm{CI}$ & & $21.9507-685.3493$ & \\
\hline T-test & & 2.158 & \\
\hline P-value & & $0.04^{\mathrm{a}}$ & \\
\hline $\mathrm{CV}$ average postoperative & $25.3(-7.5 \%)$ & & 28.2 \\
\hline Standard deviation & 6.197580173 & & 4.843552415 \\
\hline Standard error & & 1.759 & \\
\hline $95 \% \mathrm{CI}$ & & $-0.6606-6.4606$ & \\
\hline T-test & & 1.649 & \\
\hline P-value & & 0.1 & \\
\hline AVG average postoperative & $403.75(-12.5 \%)$ & & 418.3 \\
\hline Standard deviation & 118.5752398 & & 125.7756336 \\
\hline Standard error & & 38.652 & \\
\hline $95 \% \mathrm{CI}$ & & $-63.6970-92.7970$ & \\
\hline T-test & & 0.376 & \\
\hline P-value & & 0.7 & \\
\hline HEX average postoperative & $65.25(-4.19 \%)$ & & 69.15 \\
\hline Standard deviation & 6.08173495 & & 4.475209492 \\
\hline Standard error & & 1.688 & \\
\hline $95 \% \mathrm{CI}$ & & $0.4820-7.3180$ & \\
\hline T-test & & 2.31 & \\
\hline P-value & & $0.03^{\mathrm{a}}$ & \\
\hline CT average postoperative & 572.95 & & 567.8 \\
\hline Standard deviation & $59.23721381(+2.52 \%)$ & & 66.45720427 \\
\hline Standard error & & 19.907 & \\
\hline $95 \% \mathrm{CI}$ & & $-45.4492-35.1492$ & \\
\hline T-test & & -0.259 & \\
\hline P-value & & 0.8 & \\
\hline
\end{tabular}

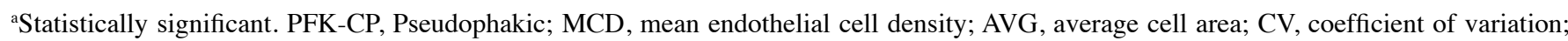
HEX, hexagonal cells; CT, corneal thickness; CI, confidence interval.

For the CT parameter, a slight increase was observed both immediately postoperatively (with $2.52 \%$ ) (Table I) and after 3 months (with $4.25 \%$ ) (Table II).

Postoperatively, a statistically significant decrease in the parameters $\operatorname{MCD}(\mathrm{P}=0.04)$ and $\operatorname{HEX}(\mathrm{P}=0.03)$ (Table I) was identified. A linear decrease in the other parameters $(\mathrm{CV}$, AVG) was evident, but these were statistically insignificant (Table I).

After 3 months postoperatively, a statistically significant decrease was observed at the following analyzed parameters: MCD ( $\mathrm{P}=0.04)$, HEX $(\mathrm{P}=0.002)$ (Table II). The remaining parameters also had a linear decrease (AVG, CV), but were statistically insignificant. Furthermore, after 3 months postoperatively, the CT parameter had a slight increase (Table II).

Comparison of values of the analyzed parameters depending on the lens. Prior to retinal detachment surgery, pseudophakic patients had a greater decrease in MCD, AVG, CV, HEX parameters (Tables III-VII) in comparison with those who had their own lens and underwent the same surgery for retinal detachment. The decrease was observed both immediately postoperatively and after 3 months postoperatively, but this decrease was statistically insignificant. In all patients, the presence of a slight constant postoperative inflammation and increased intraocular pressure immediately postoperatively was observed.

\section{Discussion}

The direct effect of silicone oil on the corneal endothelium in direct touch (39-41) has been studied before, but there are very few studies showing the effect of silicone oil in the vitreous cavity of phakic and pseudophakic eyes on endothelium. Consequently, in the present study, the changes that may 
Table II. Comparison between the 3 months postoperative values of the analyzed parameters for all patients.

\begin{tabular}{|c|c|c|c|}
\hline Variables & Operated eye & & Non-operated eye \\
\hline MCD average 3 months postoperative & $2,119.55(-3.61 \%)$ & & $2,478.6$ \\
\hline Standard deviation & 587.5921609 & & 455.2281186 \\
\hline Standard error & & 166.207 & \\
\hline $95 \% \mathrm{CI}$ & & $22.5810-695.5190$ & \\
\hline T-test & & 2.16 & \\
\hline P-value & & $0.04^{\mathrm{a}}$ & \\
\hline $\mathrm{CV}$ average 3 months postoperative & $23.5(-14.08 \%)$ & & 28.5 \\
\hline Standard deviation & 5.599107072 & & 4.82182538 \\
\hline Standard error & & 1.652 & \\
\hline $95 \% \mathrm{CI}$ & & $-0.3448-6.3448$ & \\
\hline T-test & & 1.816 & \\
\hline P-value & & $0.07^{\mathrm{a}}$ & \\
\hline AVG average 3 months postoperative & $394.6(-14.04 \%)$ & & 418 \\
\hline Standard deviation & 116.9621306 & & 125.8046104 \\
\hline Standard error & & 38.41 & \\
\hline $95 \% \mathrm{CI}$ & & $-54.3575-101.1575$ & \\
\hline T-test & & 0.609 & \\
\hline P-value & & 0.5 & \\
\hline HEX average 3 months postoperative & $62.8(-7.78 \%)$ & & 68.65 \\
\hline Standard deviation & 6.257795139 & & 4.901785389 \\
\hline Standard error & & 1.777 & \\
\hline $95 \% \mathrm{CI}$ & & $2.2517-9.4483$ & \\
\hline T-test & & 3.291 & \\
\hline P-value & & $0.002^{\mathrm{a}}$ & \\
\hline CT average 3 months postoperative & $582.6(+4.25 \%)$ & & 575.85 \\
\hline Standard deviation & 60.75063786 & & 65.25049808 \\
\hline Standard error & & 19.935 & \\
\hline $95 \% \mathrm{CI}$ & & $-47.068-33.3068$ & \\
\hline T-test & & -0.339 & \\
\hline$P$ value & & 0.74 & \\
\hline
\end{tabular}

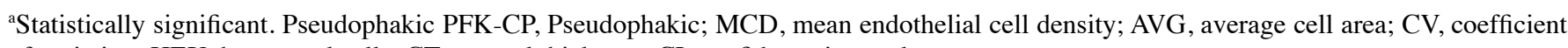
of variation; HEX, hexagonal cells; CT, corneal thickness; CI, confidence interval.

Table III. Comparison between the values of the analyzed parameters, depending on the type of lens.

\begin{tabular}{|c|c|c|c|c|}
\hline \multirow[b]{2}{*}{ Variable } & \multicolumn{2}{|c|}{ Non-operated eye } & \multicolumn{2}{|c|}{ Operated eye } \\
\hline & Phakic & PFK-CP & Phakic & PFK-CP \\
\hline MCD average postoperative & $2,309.33$ & $1,965.87$ & $2,517.83$ & $2,537.2$ \\
\hline Standard deviation & 494.86 & 599.77 & 515.21 & 382.27 \\
\hline Standard error & \multicolumn{2}{|c|}{245.61} & \multicolumn{2}{|c|}{213.62} \\
\hline $95 \% \mathrm{CI}$ & \multicolumn{2}{|c|}{-844.14 to- 246.48} & \multicolumn{2}{|c|}{-394.34 to -480.25} \\
\hline T-test & \multicolumn{2}{|c|}{-1.39} & \multicolumn{2}{|c|}{0.09} \\
\hline P-value & \multicolumn{2}{|c|}{0.18} & \multicolumn{2}{|c|}{0.93} \\
\hline MCD average 3 months postoperative & $2,239.08$ & $1,940.25$ & $2,461.41$ & $2,504.37$ \\
\hline Standard deviation & 554.69 & 589.96 & 498.87 & 379.02 \\
\hline Standard error & \multicolumn{2}{|c|}{259.56} & \multicolumn{2}{|c|}{208.14} \\
\hline $95 \% \mathrm{CI}$ & \multicolumn{2}{|c|}{-844.14 to -246.48} & \multicolumn{2}{|c|}{-394.34 to -480.25} \\
\hline T-test & \multicolumn{2}{|c|}{-1.15} & \multicolumn{2}{|c|}{0.21} \\
\hline P-value & \multicolumn{2}{|c|}{0.26} & \multicolumn{2}{|c|}{0.84} \\
\hline
\end{tabular}

PFK-CP, Pseudophakic; MCD, mean endothelial cell density; CI, confidence interval. 
Table IV. Comparison between the values of the analyzed parameters, depending on the type of lens.

\begin{tabular}{|c|c|c|c|c|c|}
\hline \multirow[b]{2}{*}{ Variables } & \multicolumn{2}{|c|}{ Non-operated eye } & \multicolumn{3}{|c|}{ Operated eye } \\
\hline & Phakic & PFK-CP & Phakic & & PFK-CP \\
\hline $\mathrm{CV}$ average postoperative & 27.41 & 22.12 & 28.5 & & 27.75 \\
\hline Standard deviation & 6.31 & 4.39 & 5.61 & & 3.34 \\
\hline Standard error & \multicolumn{2}{|c|}{2.57} & \multicolumn{3}{|c|}{2.21} \\
\hline $95 \% \mathrm{CI}$ & \multicolumn{2}{|c|}{-10.71 to -0.12} & \multicolumn{3}{|c|}{-5.40 to -3.90} \\
\hline T-test & \multicolumn{2}{|c|}{-2.05} & \multicolumn{3}{|c|}{-0.33} \\
\hline P-value & \multicolumn{2}{|c|}{$0.05^{\mathrm{a}}$} & \multicolumn{3}{|c|}{0.74} \\
\hline $\mathrm{CV}$ average 3 months postoperative & 24.25 & 22.37 & 28.83 & & 28 \\
\hline Standard deviation & 6.64 & 3.15 & 5.01 & & 4.47 \\
\hline Standard error & \multicolumn{2}{|c|}{2.53} & \multicolumn{3}{|c|}{2.19} \\
\hline $95 \% \mathrm{CI}$ & \multicolumn{2}{|c|}{-7.2 to -3.45} & \multicolumn{3}{|c|}{-5.44 to -3.77} \\
\hline T-test & \multicolumn{2}{|c|}{-0.73} & \multicolumn{3}{|c|}{-0.38} \\
\hline P-value & \multicolumn{2}{|c|}{0.47} & \multicolumn{3}{|c|}{0.71} \\
\hline
\end{tabular}

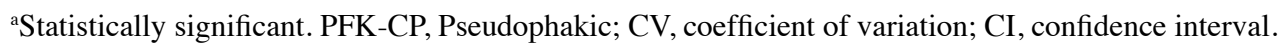

Table V. Comparison between the values of the analyzed parameters, depending on the type of lens.

\begin{tabular}{|c|c|c|c|c|}
\hline \multirow[b]{2}{*}{ Variables } & \multicolumn{2}{|c|}{ Non-operated eye } & \multicolumn{2}{|c|}{ Operated eye } \\
\hline & Phakic & PFK-CP & Phakic & PFK-CP \\
\hline AVG average postoperative & 414.16 & 388.12 & 428 & 403.75 \\
\hline Standard deviation & 142.68 & 64.85 & 150.86 & 71.1 \\
\hline Standard error & \multicolumn{2}{|c|}{54.15} & \multicolumn{2}{|c|}{57.5} \\
\hline $95 \% \mathrm{CI}$ & \multicolumn{2}{|c|}{-139.81 to -87.73} & \multicolumn{2}{|c|}{-145.07 to -96.57} \\
\hline T-test & \multicolumn{2}{|c|}{0.48} & \multicolumn{2}{|c|}{-0.42} \\
\hline P-value & \multicolumn{2}{|c|}{0.60} & \multicolumn{2}{|c|}{0.67} \\
\hline AVG average 3 months postoperative & 401.08 & 384.87 & 428.75 & 401.87 \\
\hline Standard deviation & 141.8 & 62.28 & 150.44 & 71.99 \\
\hline Standard error & \multicolumn{2}{|c|}{53.61} & \multicolumn{2}{|c|}{57.45} \\
\hline $95 \% \mathrm{CI}$ & \multicolumn{2}{|c|}{-128.84 to -96.43} & \multicolumn{2}{|c|}{-147.59 to -93.84} \\
\hline T-test & \multicolumn{2}{|c|}{-0.3} & \multicolumn{2}{|c|}{-0.46} \\
\hline P-value & \multicolumn{2}{|c|}{0.76} & \multicolumn{2}{|c|}{0.64} \\
\hline
\end{tabular}

PFK-CP, Pseudophakic; AVG, average cell area; CI, confidence interval.

occur in the corneal endothelium following retinal detachment surgery adjusted with silicone oil in phakic or pseudophakic patients were examined.

In the present study, we found a significant loss of endothelial cells, as demonstrated by the decrease in MCD, CV, AVG and HEX parameters. During the follow-up period, there were no significant complications caused by the use of silicone oil, except for a slight ocular inflammation, present almost constantly in all operated patients.

In 2014, Goezinne et al (42) who studied five groups of patients showed that the highest loss in MCD at postoperative 12 months was observed in aphakic eyes (39.2\%), followed by pseudophakic eyes (19.2\%) that underwent cataract surgery during the follow-up period. The eyes that were pseudophakic at the beginning of the study showed an MCD loss of $4.6 \%$. In any case, phakic eyes showed no significant difference. The silicone oil tamponade eyes in the present study included both phakic and pseudophakic eyes, in which a statistically significant reduction $(3.61 \%)$ in MCD at 3 months postoperatively was found, compared with baseline.

In 2017, Shaheer et al (43) who studied two groups of patients reported that MCD was decreased in both the groups showing a cell loss of $30.48 \pm 25.78$ in phakic patients group and $77.52 \pm 40.03$ in pseudophakic patients group, but the decrease in the endothelial cell count was statistically insignificant. Findings of the present study demonstrate statistically significant reduction on MCD both in the phakic and pseudophakic groups. 
Table VI. Comparison between the values of the analyzed parameters (HEX), depending on the type of lens.

\begin{tabular}{|c|c|c|c|c|c|}
\hline \multirow[b]{2}{*}{ Variables } & \multicolumn{2}{|c|}{ Non-operated eye } & \multicolumn{3}{|c|}{ Operated eye } \\
\hline & Phakic & PFK-CP & Phakic & & PFK-CP \\
\hline HEX average postoperative & 66.25 & 63.75 & 69.67 & & 68.37 \\
\hline Standard deviation & 4.88 & 7.27 & 3.19 & & 5.81 \\
\hline Standard error & \multicolumn{2}{|c|}{2.70} & \multicolumn{3}{|c|}{2.01} \\
\hline $95 \% \mathrm{CI}$ & \multicolumn{2}{|c|}{-8.18 to -3.18} & \multicolumn{3}{|c|}{-5.51 to -2.93} \\
\hline T-test & \multicolumn{2}{|c|}{0.92} & \multicolumn{3}{|c|}{-0.64} \\
\hline P-value & \multicolumn{2}{|c|}{0.36} & \multicolumn{3}{|c|}{0.52} \\
\hline HEX average 3 months postoperative & 63.75 & 61.37 & 65.58 & & 67.25 \\
\hline Standard deviation & 3.58 & 8.67 & 3.09 & & 6.51 \\
\hline Standard error & \multicolumn{2}{|c|}{2.78} & \multicolumn{3}{|c|}{2.15} \\
\hline $95 \% \mathrm{CI}$ & \multicolumn{2}{|c|}{-8.21 to -3.46} & \multicolumn{3}{|c|}{-6.86 to -2.2} \\
\hline T-test & \multicolumn{2}{|c|}{-0.85} & \multicolumn{3}{|c|}{-1.08} \\
\hline P-value & \multicolumn{2}{|c|}{0.4} & \multicolumn{3}{|c|}{0.29} \\
\hline
\end{tabular}

PFK-CP, Pseudophakic; HEX, hexagonal cells; CI, confidence interval.

Table VII. Comparison between the values of the analyzed parameters (CT), depending on the type of lens.

\begin{tabular}{|c|c|c|c|c|}
\hline \multirow[b]{2}{*}{ Variables } & \multicolumn{2}{|c|}{ Non-operated eye } & \multicolumn{2}{|c|}{ Operated eye } \\
\hline & Phakic & PFK-CP & Phakic & PFK-CP \\
\hline $\mathrm{CT}$ average postoperative & 578.41 & 564.75 & 571.91 & 561.62 \\
\hline Standard deviation & 45.59 & 74.44 & 46.8 & 87.69 \\
\hline Standard error & \multicolumn{2}{|c|}{26.71} & \multicolumn{2}{|c|}{30.03} \\
\hline $95 \% \mathrm{CI}$ & \multicolumn{2}{|c|}{-69.79 to -42.45} & \multicolumn{2}{|c|}{-73.39 to -52.81} \\
\hline T-test & \multicolumn{2}{|c|}{-0.51} & \multicolumn{2}{|c|}{-0.34} \\
\hline$P$ value & \multicolumn{2}{|c|}{0.61} & \multicolumn{2}{|c|}{0.73} \\
\hline CT average 3 months postoperative & 587.91 & 574.62 & 579.66 & 570.12 \\
\hline Standard deviation & 44.21 & 78.67 & 47.94 & 84.51 \\
\hline Standard error & \multicolumn{2}{|c|}{27.39} & \multicolumn{2}{|c|}{29.51} \\
\hline $95 \% \mathrm{CI}$ & \multicolumn{2}{|c|}{-70.83 to -44.25} & \multicolumn{2}{|c|}{-71.55 to -52.47} \\
\hline T-test & \multicolumn{2}{|c|}{-0.48} & \multicolumn{2}{|c|}{-0.32} \\
\hline P-value & \multicolumn{2}{|c|}{0.63} & \multicolumn{2}{|c|}{0.75} \\
\hline
\end{tabular}

PFK-CP, Pseudophakic; CT, corneal thickness; CI, confidence interval.

Silicone oils are powerful tools when used wisely and within the limits of their use. These are often recommended in cases of severe detachment of the retina in patients at high risk of experiencing intraoperative complications. Regular monitoring of these patients is therefore essential, especially when prolonged tamponade is required.

In the present study, we have found a linear decrease in all parameters followed (MCD, AVG, CV, HEX), both immediately postoperatively and after 3 months postoperatively.

The decrease was not statistically significant at all. At MCD, it was statistically significant both immediately postoperatively $(\mathrm{P}=0.04)$ and after 3 months postoperatively $(\mathrm{P}=0.04)$. For HEX, we also observed a statistically significant decrease immediately postoperatively $(\mathrm{P}=0.03)$, and a statistically significant high after 3 months $(\mathrm{P}=0.002)$. There was also a greater decrease in patients previously operated on for cataracts; thus, the irido-crystalline diaphragm provides protection against the decrease in the number of endothelial cells during retinal detachment surgery (44).

The study has some limitations. First of all, the low number of patients on whom it was performed. In addition, the duration of the surgery was not measured, which also contributes to the decrease in the number of endothelial cells. Another limitation is the low number of pseudophakic patients included in the study. In conclusion, posterior vitrectomy with internal silicone oil tamponade causes a decrease in the number of endothelial cells. Other factors, such as fluid turbulence, phototoxicity, changes in temperature and $\mathrm{pH}$ 
can also affect the corneal endothelium (45). Further studies are needed to demonstrate potential side effects on the anterior ocular segment of interventions in the posterior ocular segment.

\section{Acknowledgements}

Professional editing, linguistic and technical assistance performed by Irina Radu, Individual Service Provider, certified translator in Medicine and Pharmacy (certificate credentials: Series E no. 0048).

\section{Funding}

No funding was received.

\section{Availability of data and materials}

All data and materials supporting the results of the present study are available in the published article.

\section{Authors' contributions}

$\mathrm{CCC}$ and $\mathrm{OM}$ conceived and designed the study and were responsible for the interpretation and acquisition of the data. CCC, OM and SN assessed the authenticity of all data. SN and OM provided scientific advice. SIP, HF, CR were involved in the design of the study, analysis of the data, and revised the manuscript. DM, SS, SN, OLK were also involved in the conception and drafting of the study and revised the manuscript. All authors read and approved the final manuscript.

\section{Ethics approval and consent to participate}

This study was approved by the Local Ethics Committee of 'Dr. Carol Davila' Central University Military Emergency Universal Hospital, Bucharest (no. 401) and was conducted in accordance with the Declaration of Helsinki and with the International Standard of Good Clinical Practice (ICH-GCP E6 Step 4). All subjects expressed their informed consent in writing.

\section{Patient consent for publication}

Not applicable.

\section{Competing interests}

The authors declare that they have no competing interests.

\section{Authors' information}

Dr Corina Cristina Coman (Cernat) is a $\mathrm{PhD}$ student at the Department of Ophthalmology of 'Victor Babes' University of Medicine and Pharmacy in Timisoara, Romania.

\section{References}

1. Lucke $\mathrm{KH}$, Forester $\mathrm{MH}$ and Laqua $\mathrm{H}$ : Long-term results of vitrectomy and silicone oil in 500 cases of complicated retinal detachments. Am J Ophthalmol 104: 624-633, 1987.
2. Sell CH, McCuen BW II, Landers MB III and Machemer R: Long-term results of successful vitrectomy with silicone oil for advanced proliferative vitreoretinopathy. Am J Ophthalmol 103: 24-28, 1987.

3. Azen SP, Scott IU, Flynn HW Jr, Lai MY, Topping TM, Benati L, Trask DK and Rogus LA: Silicone oil in the repair of complex retinal detachments. A prospective observational multicentric study. Opthalmology 105: 1587-1597, 1998.

4. Zivojnović R: Silicone oil in vitreoretinal surgery. Springer Netherlands, 1987. doi:10.1007/978-94-009-3321-7.

5. Stone W Jr: Alloplasty in surgery of the eye. N Engl J Med 258: 486-490, 1958

6. Cibis PA, Becker B, Okun E and Canaan S: The use of liquid silicone in retinal detachment surgery. Arch Ophthalmol 68: 590-599, 1962.

7. Ryan JS: Silicone oils: Physicochemical properties. In: Retina. vol. 3, Elsevier Mosby, 4th edition, pp2191-2210, 2006.

8. Vitrectomy with silicone oil or sulfur hexafluoride gas in eyes with severe vitreoretinopathy: Results of a randomized clinical trial. Silicone study report 1. Arch Ophthalmol 110: 770-779, 1992.

9. Vitrectomy with silicone oil or perfluoropropane gas in eyes with severe proliferative vitreoretinopathy: Results of a randomized clinical trial. Silicone study report 2 . Arch Ophthalmol 110: 780-792, 1992.

10. Foster WJ: Vitreous substitutes. Expert Rev Ophthalmol 3: 211-218, 2008.

11. Nadal J, Verdaguer P and Canut MI: Treatment of retinal detachment secondary to macular hole in high myopia: Vitrectomy with dissection of the inner limiting membrane to the edge of the staphyloma and long-term tamponade. Retina 32: 1525-1530, 2012

12. Wei Y, Li Y and Chen F: Vitrectomy treatment of retinal detachments related to choroidal coloboma involving the disk. Retina 34: 1091-1095, 2014.

13. Unlü N, Kocaoğlan H, Acar MA, Sargin M, Aslan BS and Duman S: Outcome of complex retinal detachment surgery after silicone oil removal. Int Ophthalmol 25: 33-36, 2004.

14. Kapur R, Birnbaum AD, Goldstein DA, Tessler HH, Shapiro MJ, Ulanski LJ and Blair MP: Treating uveitis-associated hypotony with pars plana vitrectomy and silicone oil injection. Retina 30: 140-145, 2010.

15. Wilkinson C: Interventions for asymptomatic retinal breaks and lattice degeneration for preventing retinal detachment. Cochrane Database Syst Rev: CD003170, 2001.

16. Saw SM, Gazzard G, Wagle AM, Lim J and Au Eong KG: An evidence-based analysis of surgical interventions for uncomplicated rhegmatogenous retinal detachment. Acta Ophthalmol Scand 84: 606-612, 2006

17. García-Arumí J, Martínez-Castillo V, Boixadera A, Blasco H, Marticorena J, Zapata MÁ, Macià C, Badal J, Distéfano L, Rafart JM, et al: Rhegmatogenous retinal detachment treatment guidelines. Arch Soc Esp Oftalmol 88: 11-35, 2013 (In English, Spanish).

18. Ryan SJ: Retina. @a ed., vol III. CD ROM, Mosby, USA, 2004: 653-670, 2004

19. Polkinghorne PJ and Craig JP: Northern New Zealand rhegmatogenous retinal detachment study: Epidemiology and risk factors. Clin Exp Ophthalmol 32: 159-163, 2004.

20. Wong TY, Tielsch JM and Schein OD: Racial difference in the incidence of retinal detachment in Singapore. Arch Ophthalmol 117: 379-383, 1999.

21. Peters AL: Retinal detachment in black South Africans. S Afr Med J 85: 158-159, 1995.

22. Preda MA, Popa G, Karancsi OL, Musat O, Popescu SI, Munteanu M and Popa Z: Effectiveness of subconjunctival bevacizumab associated with a laser-based procedure in the treatment of neovascular glaucoma. Farmacia 66: 621-626, 2018.

23. Boruga O, Bălăsoiu AT, Giuri S, Munteanu M, Stanca HT, Iovanescu $\mathrm{G}$ and Preda MA: Caruncular late-onset junctional nevus: Apropos of an anatomo-clinical observation. Rom J Morphol Embryol 58: 1461-1464, 2017.

24. Balica NC, Poenaru M, Preda MA, Boia RE, Burlacu ON, Horhat ID, Mogoantă CA, Vlăescu AN, Baderca F, Jifcu EM and Sarău CA: Primary tonsillar tuberculosis-case report. Rom J Morphol Embryol 60: 267-271, 2019.

25. Stanca HT, Munteanu M, Jianu DC, Motoc AGM, Jecan CR, Tăbăcaru B, Stanca S and Preda MA: Femtosecond-LASIK outcomes using the VisuMax ${ }^{\circledR}$-MEL ${ }^{\circledR} 80$ platform for mixed astigmatism refractive surgery. Rom J Morphol Embryol 59: 277-283, 2018. 
26. Stanca HT, Suvac E, Munteanu M, Jianu DC, Motoc AGM, Roşca GC and Boruga O: Giant cell arteritis with arteritic anterior ischemic optic neuropathy. Rom J Morphol Embryol 58: 281-285, 2017.

27. Preda MA, Karancsi OL, Munteanu M and Stanca HT: Clinical outcomes of micropulse transscleral cyclophotocoagulation in refractory glaucoma-18 months follow-up. Lasers Med Sci 35: 1487-1491, 2020.

28. Stanca HT, Munteanu M, Jianu DC, Motoc AGM, Tăbăcaru B, Stanca S, Ungureanu E, Boruga VM and Preda MA: New perspectives in the use of laser diode transscleral cyclophotocoagulation. A prospective single center observational cohort study. Rom J Morphol Embryol 59: 869-887, 2018.

29. Balica NC, Poenaru M, Doroş CI, Baderca F, Preda MA, Iovan VC, Stanca HT, Busuioc CJ, Oprișcan IC and Boruga O: The management of the oropharyngeal anterior wall cancer. Rom J Morphol Embryol 59: 113-119, 2018.

30. Duan A, She H and Qi Y: Complications after heavy silicone oil tamponade in complicated retinal detachment. Retina 31 $547-552,2011$

31. Han DP, Lewis H, Lambrou FH Jr, Mieler WF and Hartz A: Mechanisms of intraocular pressure elevation after pars plana vitrectomy. Ophthalmology 96: 1357-1362, 1989.

32. Muether PS, Hoerster R, Kirchhof B and Fauser S: Course of intraocular pressure after vitreoretinal surgery: Is early postoperative intraocular pressure elevation predictable? Retina 31: 1545-1552, 2011

33. Barać J, Katusić D, Ivancić D, Sisljagić V and Bradvica M: Effect of intraocular silicone oil on ocular tissue. Coll Antropol 29 (Suppl 1): S51-S54, 2005.

34. Kleinberg TT, Tzekov RT, Stein L, Ravi N and Kaushal S: Vitreous substitutes: A comprehensive review. Surv Ophthalmol 56 300-323, 2011.

35. Caramoy A, Kearns VR, Chan YK, Hagedorn N, Poole RJ, Wong D, Fauser S, Kugler W, Kirchhof B and Williams RL: Development of emulsification resistant heavier-than-water tamponades using high molecular weight silicone oil polymers. J Biomater Appl 30: 212-220, 2015.
36. Light DJ: Silicone oil emulsification in the anterior chamber after vitreoretinal surgery. Optometry 77: 446-449, 2006.

37. Bennett SR and Abrams GW: Band keratopathy from emulsified silicone oil. Arch Ophthalmol 108: 1387, 1990.

38. Azuara-Blanco A, Dua HS and Pillai CT: Pseudo-endothelial dystrophy associated with emulsified silicone oil. Cornea 18: 493-494, 1999.

39. Kertes PJ and Peyman GA: Complications of silicone oil use. In: Vitreoretinal Surgical Techniques. Peyman GA, Meffert SA, Conway MD and Chou F (eds). Dunitz, London, pp200-203, 2006.

40. Sternberg P Jr, Hatchell DL, Foulks GN and Landers MB III: The effect of silicone oil on the cornea. Arch Ophthalmol 103: 90-94, 1985.

41. Pang MP, Peyman GA and Kao GW: Early anterior segment complications after silicone oil injection. Can J Ophthalmol 21: 271-275, 1986.

42. Goezinne F, Nuijts RM, Liem AT, Lundqvist IJ, Berendschot TJ, Cals DW, Hendrikse F and La Heij EC: Corneal endothelial cell density after vitrectomy with silicone oil for complex retinal detachments. Retina 34: 228-236, 2014

43. Shaheer M, Khan AA, Ahmed N, Mahju TM and Rasheed U: Corneal endothelial cell loss after vitrectomy with silicone oil tamponade in phakic versus pseudophakic patients with rhegmatogenous retinal detachment. Pak J Ophthalmol 33: 137-141, 2017.

44. Goyal JI, Panda A and Angra SK: Corneal endothelial changes following pars plana lensectomy. Indian J Ophthalmol 39: 25-27, 1991.

45. Kwon JW, Cho KJ, Kim HK, Lee JK, Gore PK, McCartney MD and Chuck RS: Analyses of factors affecting endothelial cell density in an eye bank corneal donor database. Cornea 35: $1206-1210,2016$

c) (†) $\Theta$ This work is licensed under a Creative Commons

CC NG ND Atribution-NonCommercial-NoDerivatives 4.0 International (CC BY-NC-ND 4.0) License. 